\title{
Spatiotemporal Variations of Drought in Inner Mongolia over the Past 50 years Based on SPEI
}

Siqin Tong, Jiquan Zhang*, Quan Lai, Rina Wu

College of Environment, Northeast Normal University; Institute of Natural Disaster Research, Northeast Normal University, Changchun 130024, China

\section{基于 SPEI 指数的近 50 年内蒙古 干旱时空变化特征}

\author{
佟斯琴, 张继权 ${ }^{*}$, 来全, 乌日娜
}

东北师范大学环境学院, 东北师范大学自然灾害研究所, 长春 130024 , 中国

\begin{abstract}
The Standardized Precipitation Evapotranspiration Index (SPEI) was used as the indicator of drought, calculating the monthly precipitation and monthly mean temperature among the 109 weather stations in Inner Mongolia from 1961 to 2010 to obtain the SPEI value of each site at the time scale of 12 month. Then according to the temporal and spatial change trend of SPEI, spatial distribution and drought occurrence frequencies, this paper analyzed the spatial-temporal variation characteristics of drought in Inner Mongolia. The results showed that: 1)over the past 50 years in Inner Mongolia the drought is decreasing at a rate of $0.22 / 10 \mathrm{a}$, becoming more and more dryer, the occurrence of different grades of drought has increased, and most prominent in early twenty-first century. 2) There was a clear mutation in 1998 and after this year the occurrence frequency of extreme drought and severe drought increased, showing that the drought in Inner Mongolia is exacerbated since the 1998. 3) There is significant regional differences of drought interannual variability in spatial distribution
\end{abstract}

*通讯作者: 张继权, Zhangjq022@nenu.edu.cn from 1961 to 2010, in short, the drought degree in east of Inner Mongolia is higher than that of west in study area. 4) During 1961 to 2010 the SPEI in Inner Mongolia has a different degree of reducing trend, which means that the whole area of the region tends to be dry since the 60's. Keywords: Standardized Precipitation Evapotranspiration Index; drought; spatial-temporal variation; Inner Mongolia

\section{摘要}

以标准化降水蒸散指数(SPEI)作为干旱的评 价指标, 通过对 1961-2010 年内蒙古 109 个 气象站逐月降水量和平均气温的计算, 得出 各个站点 12 月尺度 SPEI 值, 根据 SPEI 值的 变化规律、变化趋势及干旱发生频率, 对内 蒙古地区近半个世纪的干旱时空变化特征进 行了分析。结果表明: (1)内蒙古地区近 50a 来呈干旱化趋势, 不同等级干旱的次数均呈 增加趋势, 21 世纪初干旱发生最频繁。(2)在 1998 年出现明显的突变, 此后极端干旱和严 重干旱出现频率增多, 表明 1998 年后内蒙古 干旱化进一步加大。(3)空间分布存在明显的 地区差异, 整体上研究区东部干旱程度大于 西部地区。(4)近 50a 来全区 SPEI 在空间上呈 不同程度的减小趋势, 说明 60 年代以来内蒙 古地区趋于进一步干旱化。 
Risk Analysis and Crisis Response in Big Data Era (RAC-16)

关键词: 标准化降水蒸散指数; 干旱; 时空 变化; 内蒙古

\section{1. 引言}

干旱是复杂的自然灾害之一, 对农业、水资 源、自然生态系统和社会都有着极其重大的 影响, 带来庞大的经济损失、饥荒、流行病 和土地退化等负面影响 [1]。随着全球气候变 暖, 干早发生频繁, 并有明显的上升趋势[2,3]。 干早直接影响蒙古高原农牧业发展、加快荒 漠化进程并引发严重的沙尘暴[4,5]。因此, 干旱的监测和评估对减少损失、保障人类生 命和财产安全有重要作用。通常, 应用某一 指标从发生频率、持续时间、强度和波及范 围分析干旱。主要的干旱指数有 Palmer 干旱 指数 (PDSI)、地表供水指数 (SWSI)、标准 化降水指数 (SPI)、有效干旱指数 (EDI) 等 [6-8], 并广泛用于各地干旱研究中。其中, SPI 由于计算简单、具有多时间尺度特点, 被 广泛应用于气象干旱研究, 然而其只考虑降 水作为影响干旱化的唯一因素, 而忽略了由 于增温而出现的干旱化趋势, 因此, 存在一 定的局限性[9]。PDSI 尽管是公认较好的干旱 指数, 然而其本身存在计算复杂、资料要求 高、时间尺度固定[10], 适于测量极端干旱和
湿润, 因此, 在某些参数的选择和计算上受 到制约。Vicente-Serrano 等[11]提出的标准化 降水蒸散指数 SPEI(Standardized precipitation evapotranspiration index, 简称 SPEI) 指数结 合了 SPI 多时间尺度及 PDSI 对蒸散的响应等 优点, 基于概率计算, 具有空间可比性的优 点, 目前已成为研究干旱新的理想指标 $[12,13]$ 。

内蒙古自治区地处东南季风影响的季风 边缘区, 是我国西部干旱区向东北湿润区和 华北旱作农业区的过渡带, 气候变化敏感, 灾害事件常有发生 [14], 其植被和环境受气候 变化影响非常明显。其经济基础以农业、畜 牧业及矿产资源开发为主, 然而工业的发展 挤占生态用水, 加之多年持续干旱使得我区 草场退化、生态恶化问题日渐突出。尤其进 入 21 世纪以来, 内蒙古大部地区降水偏少、 气温偏高, 出现不同程度的干旱, 受灾农牧 户损失严重。鉴于此, 本文基于 SPEI 指数, 结合 Mann-Kendall (M-K) 突变检验和滑动平 均方法, 对内蒙古 1961-2010 年气象干旱的 时间和空间分布规律及变化趋势进行了分析, 以期更为全面和深入的描述内蒙古 1961-2010 年气象干旱变化规律, 从而为水资 源利用规划与干旱防灾减灾提供科学依据。

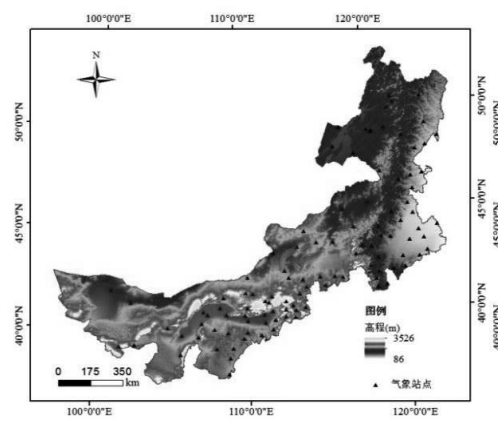

图 1 内蒙古地理位置及气象站点分布图

\section{2. 研究区概况}

内蒙古自治区位于我国北部边疆, 地域辽阔, 西起 $97^{\circ} 12^{\prime} \mathrm{E}$, 东至 $126^{\circ} 04^{\prime} \mathrm{E}$, 横跨经度 $28^{\circ} 52^{\prime}$, 相隔 $2400 \mathrm{~km}$, 南起 $37^{\circ} 24^{\prime} \mathrm{N}$, 北至 $53^{\circ} 23^{\prime} \mathrm{N}$, 纵跨纬度 $15^{\circ} 59^{\prime}$, 直线距离 $1700 \mathrm{~km}$, 是我国

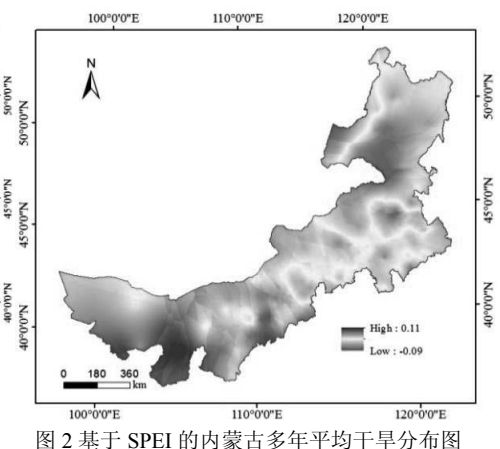

跨纬度最大的省级行政区。地势由西向东倾斜, 高程在 86 3526m 之间, 气候以温带大陆性季 风气候为主, 全区年平均气温从东北至西南递 增约为 $0 \sim 8^{\circ} \mathrm{C}$, 年降水量范围为 $50 \sim 450 \mathrm{~mm}$, 分布趋势与气温分布正好相反, 由东北向西南 递减。 


\section{3. 数据与方法}

\section{1. 数据来源}

气象数据是由中国气象科学数据共享服务网 (http://cdc.cma.gov.cn) 免费下载的研究区境 内 109 个气象站点 (图 1) 的月平均气温和月 降水量(1-12 月), 时间段为 1961-2010 年。

\subsection{SPEI 指数}

标准化降水蒸散指数(SPEI)作为表征干旱一 种多时间尺度的指标, 其计算过程同标准化降 水指数(SPI)相似, 不同的是 SPI 仅考虑了月降 水量, 而 SPEI 同时考虑了月降水量和月潜在 蒸发量。具体计算主要有如下几个步骤[11]:

（1）计算潜在蒸散发(Potential

Evapotranspiration, PET), 用 Thornthwaite 方法 求得。

$$
\mathrm{PET}=16 \mathrm{~K}\left(\frac{16 \mathrm{~T}_{\mathrm{i}}}{\mathrm{I}}\right)^{\mathrm{m}}
$$

式 (1) 中, $T_{i}$ 为月平均气温 $\left({ }^{\circ} \mathrm{C}\right)$; I 为年热量 指数; $\mathrm{i}$ 为月份; 系数 $\mathrm{m}=6.75 \mathrm{E}^{-7} \mathrm{I}^{3}-$ $7.71 \mathrm{E}^{-5} \mathrm{I}^{2}+1.79 \mathrm{E}^{-2} \mathrm{I}+0.492$, E为指数函数; $\mathrm{K}$ 为修正系数。

（2）计算水分亏缺, 为月降水量与月潜在蒸 散之差, 公式为:

$$
\mathrm{D}_{\mathrm{i}}=\mathrm{P}_{\mathrm{i}}-\mathrm{PET}_{\mathrm{i}}
$$

式 (2) 中, $\mathrm{D}_{\mathrm{i}}$ 为月水分亏缺量; $\mathrm{P}_{\mathrm{i}}$ 为月降水量; $\mathrm{PET}_{\mathrm{i}}$ 为月潜在蒸散发量, 单位均为 $\mathrm{mm}$ 。

（3）建立不同时间尺度气候学意义的水分盈 亏累积序列:

$$
\mathrm{D}_{\mathrm{n}}^{\mathrm{k}}=\sum_{\mathrm{i}=0}^{\mathrm{k}-1}\left(\mathrm{P}_{\mathrm{n}-1}-\mathrm{PET}_{\mathrm{n}-\mathrm{i}}\right), \mathrm{n} \geq \mathrm{k}
$$

式中, $\mathrm{k}$ 为时间尺度 (月); $\mathrm{n}$ 为计算次数。

(4) 将 (3) 中所建序列采用 3 个参数 log-logistic 概率密度函数拟合:

$$
f(x)=\frac{\beta}{\alpha}\left(\frac{x-\gamma}{\alpha}\right)^{\beta-1}\left[1+\left(\frac{x-\gamma}{a}\right)\right]^{-2}
$$

式中: $f(x)$ 为概率密度函数, $\alpha 、 \beta$ 和 $\gamma$ 分别为 尺度参数、形状参数和 origin 参数, 可通过线 性矩法进行估算。累积概率函数

$$
\mathrm{F}(\mathrm{x})=\left[1+\left(\frac{\mathrm{x}-\gamma}{\alpha}\right)^{\beta}\right]^{-1}
$$

(5)对序列进行标准正态分布转换, 得到相应 SPEI:

$$
\text { SPEI }=W-\frac{C_{0}+C_{1} W+C_{2} W^{2}}{1+d_{0} W+d_{2} W^{2}+d_{3} W^{3}}
$$

式中: $W=\sqrt{-2 \ln (P)}$; 当 $P \leq 0.5$ 时, $\mathrm{P}=1-\mathrm{F}(\mathrm{x})$; 当 $\mathrm{P}>0.5$ 时, $\mathrm{P}=1-\mathrm{P}, \mathrm{SPEI}$ 的 符号被逆转。常数 $\mathrm{C}_{0}=2.515517$, $\mathrm{C}_{1}=0.802853 \quad, \quad \mathrm{C}_{2}=0.010328 \quad$, $\mathrm{d}_{1}=1.432788, \quad \mathrm{~d}_{2}=0.189269, \quad \mathrm{~d}_{3}=$ 0.001308 。

不同时间尺度的 SPEI 反映了过去不同时 间长度的水分异常状态, 12 个月尺度的 SPEI 更能反映干早年际变化情况[15]。本文主要研 究干旱的年代际规律, 因此 SPEI 采用 12 个月 尺度进行计算。在计算得出 SPEI 数值后采用 Mann-Kendall 突变检验进行时间序列数据的 突变分析。并依据相关文献 $[9,16]$ 和中国气象 局制定的 SPEI 干旱等级划分标准[17]对研究 区干旱等级进行划分 (表 1)。

表 1 干旱发生等级 SPEI 值与累计概率

\begin{tabular}{cccccc}
\hline & 极端干早 & 严重干早 & 中度干旱 & 轻度干早 & 正常年份 \\
\hline SPEI & $\leq-2.0$ & $(-2.0,-1.5]$ & $(-1.5,-1.0]$ & $(-1.0,-0.5]$ & $\geq-0.5$ \\
累计概率(\%) & 2.51 & 5.25 & 10.06 & 14.20 & 67.98 \\
\hline
\end{tabular}

\section{3. 干旱发生频率}

计算干旱发生频率 $p$ 的公式如下 [18]:

$$
\mathrm{p}=\mathrm{n} / \mathrm{N} \times 100 \%
$$

式中, $n$ 为数据序列中干旱发生的次数; $N$ 为数据序列数。

\section{4. 结果分析}

\section{1. 基于 SPEI 的内蒙古干旱时间变化特征分 析}

SPEI 作为气象干旱指数, 其值越小, 干旱程 度越严重。图 3 是年尺度 SPEI 指数的历年变 化。由图可见, 1961-2010 年, 整个内蒙古地 
Risk Analysis and Crisis Response in Big Data Era (RAC-16)

区年尺度 SPEI 值有波动中显著的减小趋势, 通过 0.001 显著性水平, 下降率为 $0.22 / 10 \mathrm{a}$; 从 10a 滑动平均可知, 1994 年之前 SPEI 值波 动较平缓, 1994 年之后 SPEI 迅速下降, 并且 21 世纪初的 SPEI 值小于- 0.5 , 表明, 在 60 年 代、 70 年代、 80 年代干旱程度相对比较小, 而在 90 年代和 21 世纪初期的干旱程度比较严 重, 特别是 21 世纪初期, 干旱程度最大。

依据 SPEI 等级划分 (表 1), 按站点统计 各年代不同等级干旱发生频率, 其结果如图 4

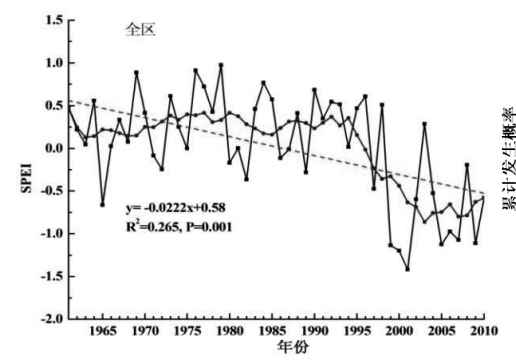

所示。除 21 世纪初期 (2001-2010 年), 其它 四个年代以轻度干旱为主, 其次为中度干旱、 严重干旱, 极端干旱发生频率最少, 且 70 年 代干旱发生频率比其他时段小, 结合其时间变 化规律可知, 70 年代是内蒙古干旱较少, 相 对湿润期。进入 21 世纪后, 各等级干旱发生 频率均比其它年代大, 且以中度干旱为主, 进 一步表明, 进入 21 世纪以来内蒙古干旱发生 最频繁。

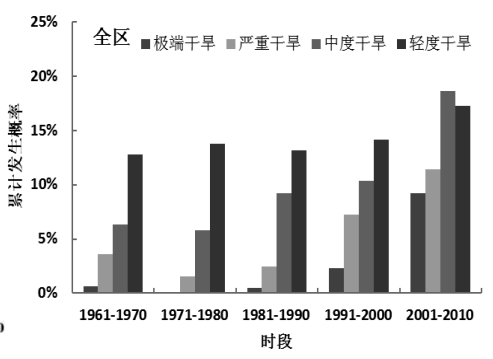

图 4 1961-2010 年内蒙古各年代不同等级干旱发生频率
采用 Mann-Kendall 法对全区年尺度 SPEI 的突变检验显示, 在显著性水平 0.05 的临界 线内, UF、UB 曲线相交于 1998 年, 并在交 点之后 UF 曲线通过 0.05 显著性水平的检验, 表明研究时间段内内蒙古地区年尺度 SPEI 指 数存在显著突变点, 即 1998 年。1998 年之前, UF 曲线缓慢上升, 而在 1998 年后 UF 曲线显

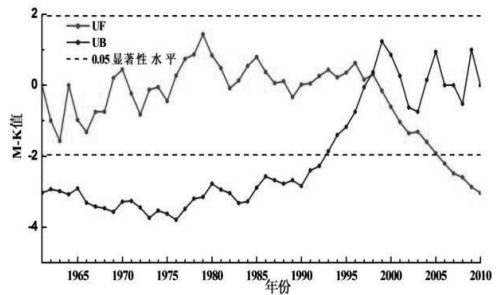

图 5 1961-2010 年内蒙古年尺度 SPEI 序列 M-K 检验
著下降。以突变年, 即 1998 年为分界点统计 突变前后内蒙古不同等级干旱发生频率可知 (图 6), 突变后极端干旱和严重干旱出现的 频率增加, 中度干旱和轻度干旱发生比突变前 有所减少, 说明 1998 年后内蒙古干旱发生频 率明显加大。



图 6 突变前后不同等级干旱发生频率

\section{2. 基于 SPEI 的内蒙古干早空间变化特征分 析}

干早空间分布特征分析。从图 2 可以分析出, 1961-2010 年内蒙古干旱年际变化在空间上存 在明显地区差异, 总体上有内蒙古东部干旱比 西部地区高的特征。不同年代 SPEI 空间分布
特征有 (图 7), 60 年代和 70 年代 SPEI 值大 体上均大于 0 , 以无旱为主; 80 年代内蒙古西 部阿拉善盟和锡林郭勒南部地区出现干旱, 到 了 90 年代干旱面积增大, 在内蒙古中西部和 兴安盟出现轻度干旱; 21 世纪初, 以轻度和 中度干旱为主, 在额济纳旗、锡林郭勒和呼伦 
Risk Analysis and Crisis Response in Big Data Era (RAC-16)

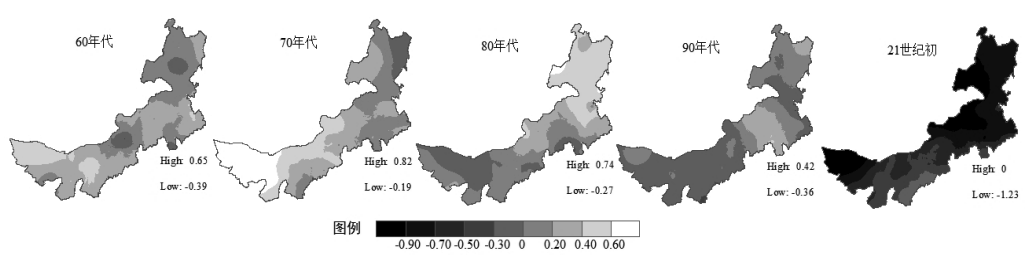

图 7 基于 SPEI 的内蒙古 60 年代、 70 年代、 80 年代、 90 年代和 21 世纪初期干旱分布图

贝尔西部出现干旱程度最大, 其次是内蒙古东 部呼伦贝尔、兴安盟、赤峰和通辽等地区干旱 较严重。综上所述, 近 50 年内蒙古干旱程度 逐渐加大, 到了 21 世纪初更加严重。

干旱频率空间分析。图 8 为近 50a 内蒙古 地区年尺度干旱频率分布图, 发现干旱频率在 空间上差异较小。主要是该区气温和降水量在 空间上存在不均衡性, 加之受地貌因素的影响, 从而导致干旱分布具有较强的局域性, 在空间 上也呈现出一定的复杂性。在 1961-2010 年内 蒙古地区干旱发生频率为 $29 \%-35 \%$, 兴安盟 的干旱发生频率较其他地区偏高, 其次是阿拉 善盟、鄂尔多斯、锡林郭勒盟东部、赤峰及通

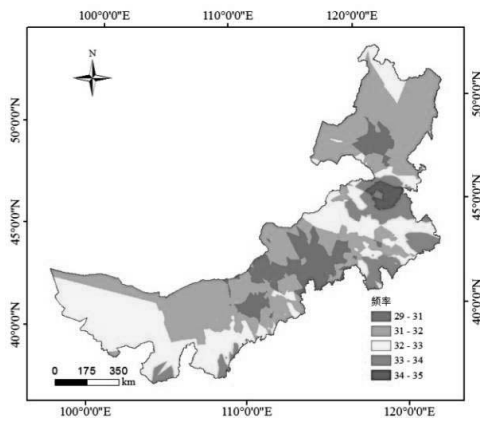

图 8 1961-2010 年内蒙古干旱发生频率分布示意图

\section{5. 结论}

本研究采用 SPEI 作为干旱指数, 对近 50 年内蒙古干 旱时空变化特征进行了研究, 得出以下主要结论:

(1) 近 50 年来内蒙古年尺度 SPEI 指数以 $0.22 / 10 \mathrm{a}$ 的速率显著下降, 表明内蒙古趋于干旱化, 且不同等 级干旱出现的频次均呈增加趋势, 进入 21 世纪以来 干旱最突出, 以轻度干旱和中度干旱为主。

（2）通过 M-K 突变检验得出, SPEI 指数在 1998 年 发生突变, 下降趋势明显, 通过 0.05 的显著性检验;
辽的干旱发生频率比其他地区高, 内蒙古东部 地区及呼伦贝尔干早发生频率相对较低。

干旱趋势空间分析。用最小二乘法计算 1961-2010 年内蒙古地区每个站点的 SPEI 变 化趋势, 并在 ArcGIS 软件正进行克里金插值, 得出内蒙古 SPEI 趋势空间分布 (图 9)。从图 8 中可以看出内蒙古干旱变化趋势存在明显差 异。109个站点中仅有 2 个站点的斜率大于 0 , 其它站点斜率均小于 0 , 且在空间插值后, 整 个内蒙古地区 SPEI 呈不同程度的减小趋势, 但不存在明显的规律。SPEI 减小趋势最大的 地区出现在额济纳旗, SPEI 变化趋势最小的 出现在赤峰市南部。

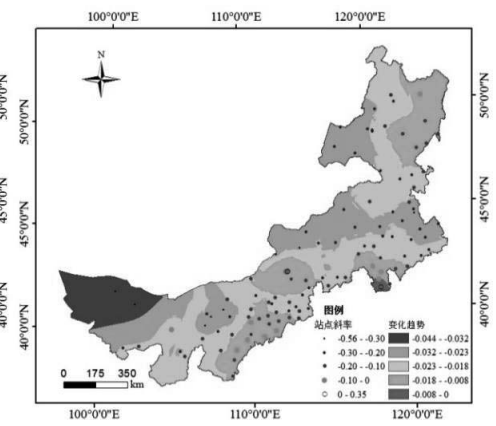

图 9 内蒙古 1961-2010 年干旱指数变化趋势

突变后极端干旱和严重干旱的出现频率增加, 干旱明 显加重。

(3) 1961-2010 年内蒙古干旱年际变化在空间上存在 明显的地区差异, 总体上由东部干旱较西部严重。

(4)1961-2010 年内蒙古干旱发生频率在空间上较一 致, 在 $29 \%$ 35\%间, 其中, 兴安盟干旱发生频率最 高, 其次是阿拉善、鄂尔多斯、赤峰、通辽和锡林郭 勒盟东部地区较高, 其余地区干旱发生频率较低; 整 个内蒙古地区 SPEI 呈不同程度的减小趋势, 其减小 趋势最大的地区出现在额济纳旗, 最小的出现在赤峰 
Risk Analysis and Crisis Response in Big Data Era (RAC-16)

市南部, 表明近 50 年来内蒙古地区呈干早化态势。

\section{Acknowledgements}

This study was supported by "Twelfth five-year" national science and technology support plan (2013BAK05B02、2013BAK05B01) and the National Non-Profit Research Program of China (No.201401015).

\section{致谢}

本文得到 “十二五”国家科技支撑计划课题 (2013BAK05B02、2013BAK05B01)和水利部公益性 行业科研专项经费项目(201401015)资助。

\section{6. 参考文献}

[1] Begueria S, Vicente-Serrano SM, Angulo M. A multi-scalar global drought data set: the SPEI base: a new gridded product for the analysis of drought variability and impacts. Bull Am Meteorol Soc ,2010, 91:1351-1354.

[2] Giannakopoulos C, Sager PL, Bindi M, et al. Climatic changes and associated impacts in the Mediterranean resulting from a $2{ }^{\circ} \mathrm{C}$ global warming. Global Planet Change, 2009, 68(3):209-224.

[3] Guo SJ. The meteorological disaster risk assessment based on the diffusion mechanism. Journal of Risk Analysis and Crisis Response, 2012, 2(2): 124-130.

[4] Shinoda M, Nachinshonhor GU, Nemoto M. Impacts of drought on vegetation dynamics of the Mongolia steppe: a field experiment. Journal of Arid Environment, 2010, 74(1):63-69.

[5] Goudie AS, Middleton NJ. The changing frequency of dust storms through time. Climate Change, 1991, 20(3):197-225.

[6] 姚玉璧, 张存杰, 邓振镛, 董安祥, 张秀云. 气象、 农业干旱指标综述. 干旱地区农业研究, 25(1): 185-189, 211, 2007.

[7] Mishra A K, Singh V P. A review of drought concepts. Journal of Hydrology, 2010 , 391(1/2):202-216.

[8] 张调风, 张勃, 王有恒, 刘秀丽, 安美玲, 张建香. 基于综合气象干旱指数的石羊河流域近 50 年气 象干旱特征分析. 生态学报, 2013,33(3): 975-984.

[9] Mckee TB, Doesken NJ, Kleist J. The relationship of drought frequency and duration to time scales. The 8th Conference on Applied Climatology, Boston: American Meteorological Society, 1993, 17(22):179-183.

[10] Palmer W C. Meteorological drought. Washington DC: Department of Commerce Weather Bureau, 1965.

[11] Vicente-serrano SM, Beguería S, López-Moreno JI.
A multiscalar drought index sensitive to global warming: The standardized precipitation evapotranspiration index. Journal of Climate, 2010, 23(7):1696-1718.

[12]石崇, 刘晓东. 1947-2006 年东半球陆地干旱化特 征一基于 SPEI 数据的分析. 中国沙漠, 2012, 32(6): 1691-1701.

[13]任培贵, 张勃, 张调风, 李小亚, 陈乐, 卢李朋. 基于 SPEI 的中国西部地区气象干旱变化趋势分 析. 水土保持通报, 2014, 34(1): 182-187, 192.

[14]银山, 香宝, 雷军, 阿拉腾图雅, 包玉海. 内蒙古 自然灾害综合分区与评价. 资源科学, 2002 , 24(3): 31-35

[15] 李伟光, 易雪, 候美亭, 陈汇林, 陈珍莉. 基于标 准化降水蒸散指数的中国干旱趋势研究. 中国生 态农业学报, 2012, 20(5):643-649.

[16]周丹, 张勃, 任培贵, 张春玲, 杨尚武, 季定民. 基于标准化降水蒸散指数的陕西省近 $50 \mathrm{a}$ 干旱特 征分析. 自然资源学报,2014,29(4):677-688.

[17]中国气象科学研究院, 国家气象中心, 中国气象 局预测减灾司. GB/T20481-2006 气象干旱等级. 北京: 中国标准出版社,2006: 39-42.

[18] 张调风, 张勃, 王小敏, 贾建英, 尹海霞, 何旭霞. 基于综合气象干旱指数 (CI) 的干旱时空动态格 局分析一以甘肃省黄土高原区为例. 生态环境学 报, 2012, 21(1): 13-20。 